\title{
AN ALTERNATIVE WAY OF MAKING BUMPS FOR TAPE AUTOMATED BONDING
}

\author{
KAREL KOPEJTKO and JINDŘICH VILÍM \\ Research Institute for Mathematical Machines, Prague, Czechoslovakia
}

(Received June 11, 1979)

\begin{abstract}
Complete testing and high speed automated assembling are the main advantages which are offered by the technology called Tape Automated Bonding (TAB). The main step in this technology is a bumping of wafers which is usually performed by the IC manufacturers. When the bumped wafers are not available, the hybrid circuit manufacturers are forced to bump wafers themselves. As the bumping process consists of several operations requiring many preliminary steps, a new bumping process which is based on ultrasonic bonding of the preformed gold bumps to the aluminium pads of chips has been suggested. Compatibility of such bumped chips with $\mathrm{TAB}$ and the shear strength of those bumps were tested.
\end{abstract}

\section{INTRODUCTION}

High yield LSI hybrid circuit production is limited by the possibility of complete testing of chips before mounting on hybrids. This is enabled by a new technology called Tape Automated Bonding (TAB). The main and critical step in this technology is the building of bonding pads (bumps) on the chip. These bumps are usually built by a combination of sputtering and electrodeposition of several metals on a chip whose surface is passivated. ${ }^{1,2}$ Gold is the usual base material for making bumps. These operations are performed on the whole wafer either immediately after the active structure has been made by the IC manufacturers or by the hybrid circuit manufacturers. From the economic point of view the first method is more profitable, but in many cases the hybrid circuit manufacturers are forced to do these operations themselves. ${ }^{3}$ The cost of these operations and their complex preparation limit the use of this technology on the high yield and large scale IC production.

Making bumps on the inner side of the lead frame is one of the ways to overcome the limitations mentioned. Another way of solving those problems was developed for the purposes of hybrid technology ${ }^{4}$ and is briefly discussed in this paper. This way is in principle based on ultrasonic bonding of the preformed gold bumps to aluminium pads of chips. The best method of bump forming was found to be the melting of a gold wire in a oxy-hydrogen flame. A definitive cylindrical shape is formed in the successive bonding step. In the cutting step the wire is then separated from the bump on the chip.

\section{EXPERIMENTAL METHOD}

\subsection{Sample Preparation}

The suggested technology was tested on the current IC with aluminium metallization. The supplied IC wafer was attached by a thin layer of heat-released adhesive to a flat substrate.

\subsection{Bump Making}

For this operation a Helmut Seier 502 ultrasonic gold wire bonder with UTI 10-C-7 generator was adapted. The operating cycle was turned into the following sequence:

- search position

- bonding position

- cutting position

- ball forming position

Two methods of cutting procedure were tested. In the first method, the second welding position was turned into an ultrasonic cutting position. It was achieved by applying a higher density of ultrasonic energy and mechanical shift on the unloaded capillary. In the second cutting method, the second bonding position was excluded and a cutting mechanism was added. ${ }^{5}$ For realisation of the definitive cylindrical shape of bumps and for ultrasonic cutting purposes, the capillary was redressed into the truncated cone shape with sharp 


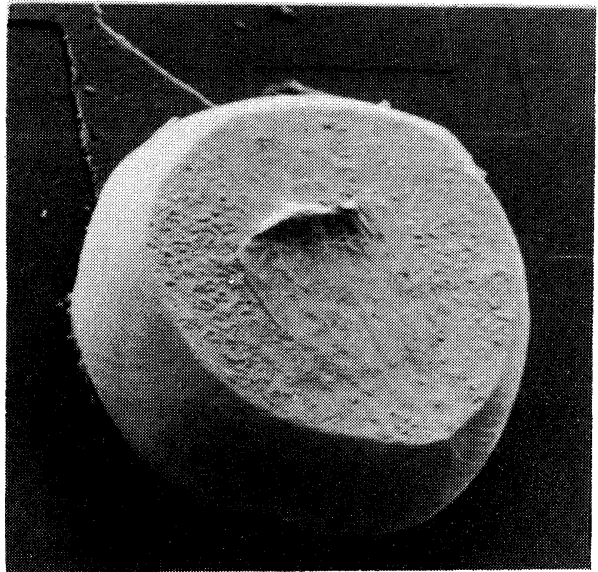

FIGURE 1a Bump with ultrasonically cut wire (SEM 400x).

edge of the hole. Demetrons $17 \mu \mathrm{m}$ gold wire was used. The dimensions of bumps were changed over a broad range according to the adjustment of the device. A typical bump with ultrasonically cut wire is shown in Figure 1a, and with mechanically cut wire in Figure $1 b$.

\subsection{TAB Compatibility Testing}

Bumped wafer was sawed through as far as the substrate. Chips were thermocompressively bonded to the pretinned copper lead frame on a polyester tape (35 mm width). Small butts of wire did no harm. After this operation no drop in bump shear strength was observed. Its typical value for the size of bump shown was higher than $80 \mathrm{~g}$.

\section{DISCUSSION}

On the basis of results achieved, it is obvious that this technology can be profitable in those special cases when bumped chips are currently not available. Although the bump making process described has been developed on a manually controlled device, all the steps were suggested with a fully automatic version in mind. In the production range, full automation is necessary. As the chip preparation described is derived from standard "flying wire" technology, no additional problems either in metallurgy or in automation can occur. The steps in a production line employing the suggested bump making process and the steps in the standard electrolytic version are compared in Table I.

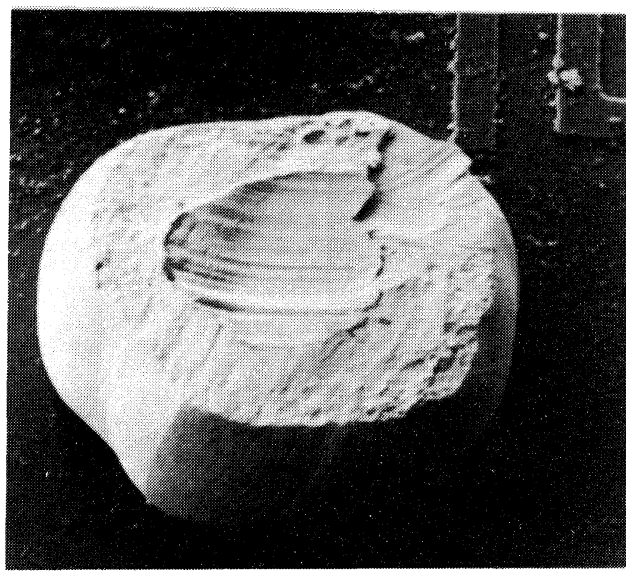

FIGURE 1b Bump with mechanically cut wire (SEM 400x).

TABLE I

Comparation of the suggested version of $\mathrm{TAB}$ with the standard one

\begin{tabular}{lc}
\hline Suggested & Standard \\
\hline active structure making \\
wafer attachment & passivation if needed \\
static parameters test & $\begin{array}{c}\text { sputter deposition of pro- } \\
\text { tect and auxiliary layers } \\
\text { photoresist lamination and } \\
\text { development }\end{array}$ \\
& $\begin{array}{c}\text { electrodeposition of bump } \\
\text { bodies } \\
\text { photoresist stripping } \\
\end{array}$ \\
& $\begin{array}{c}\text { auxiliary layers removing } \\
\text { wafer attachment }\end{array}$ \\
inner lead bonding
\end{tabular}

† bumps are bonded only to such chips that have passed through the static parameters test. Coordinates of acceptable chips are stored in a control unit.

\section{CONCLUSION}

The new alternative way of chip preparation for TAB has been suggested. Compared to the standard version it offers these advantages:

- preparation is performed only on chips which have passed through the static parameters test

- operations do not need a complex preparation

- preparation can be performed by a hybrid circuit manufacturer 
-standard "flying wire" equipment can be easily converted for this method and then this whole process can be easily incorporated into an existing production line.

These advantages make the method suitable for hybrid circuit manufacturers if standard bumped chips are not available (small series or low yield). The TAB assembly of chips is necessary for high yield of the whole hybrid.

\section{REFERENCES}

1. J. M. Montante and R. G. Oswald, Wafer bumping for tape automated bonding, Proc. 1977 International Microelectronics Symposium (Baltimore) 115-9.
2. A. van der Drift, W. G. Gelling and A. Rademakers, Integrated circuits with leads on flexible tape, Solid State Techn. (February 1976) 27-35.

3. R. F. Rademske, Technical and economic considerations in selecting automatic wire bonding systems for a custom hybrid house, Proc. 1977 International Microelectronics Symposium (Baltimore) 88-92.

4. J. Vilím and K. Kopejtko, Ceskoslov. pat. přihl. PV 732377 (Czech).

5. K. Kopejtko, T. Matoušek and J. Vilím, Českoslov. pat. prihl. PV 8484-77 (Czech). 

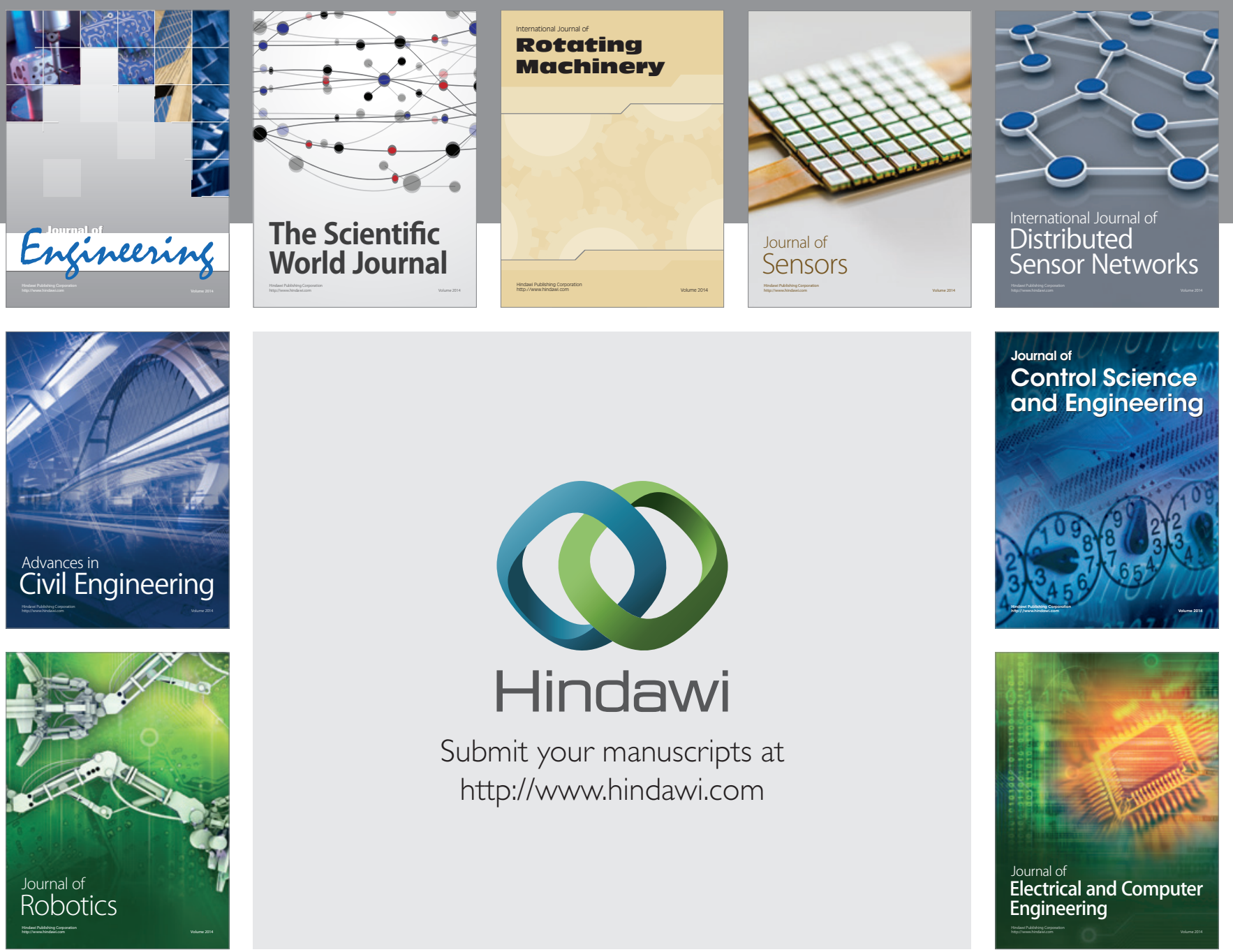

Submit your manuscripts at

http://www.hindawi.com
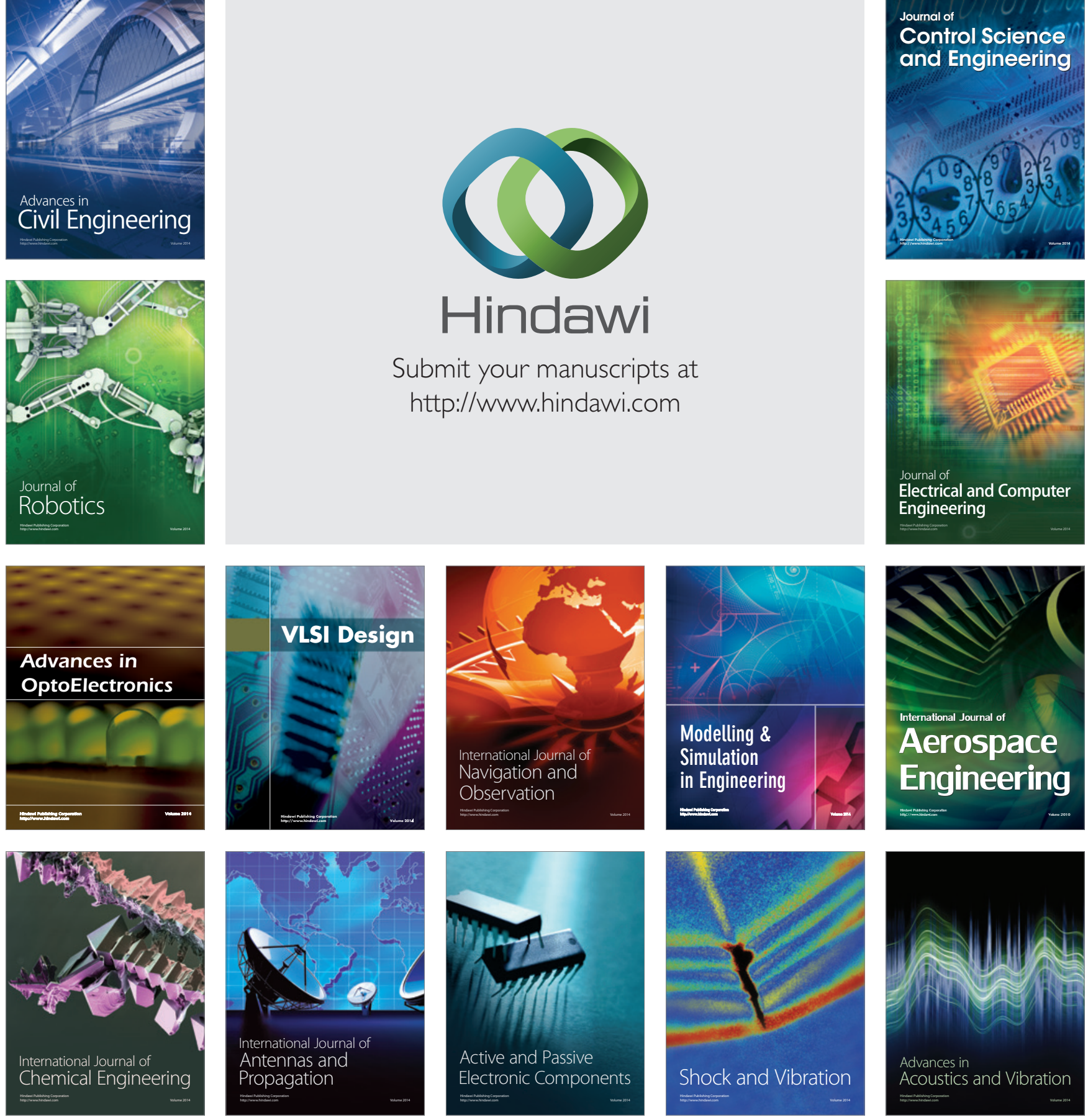